\title{
Development of multistage plowing method that involves subsurface loosening
}

\author{
Maxim P. Erzamaev 1,", Dmitry S. Sazonov ${ }^{1}$, Leila S. Kurmanova ${ }^{2}$, Evgeny S. Nesterov ${ }^{3}$, Alexey E. Shlykov ${ }^{4}$ \\ ${ }^{1}$ Samara State Agrarian University, Samara, 446442, Russia \\ ${ }^{2}$ Samara State Transport University, Samara, 443066, Russia \\ ${ }^{3}$ Saratov State Vavilov Agrarian University, Saratov, 410012, Russia \\ ${ }^{4}$ Nizhny Novgorod State Engineering and Economic University, Knyaginino, 606340, Russia
}

\begin{abstract}
The paper proposes a new method for multistage plowing that implies loosening bottom soil and subsoil horizon simultaneously, followed by overturning the bottom soil without cutting, which improves the quality of soil cultivation, softens a plow sole and reduces energy costs. Experimental studies confirmed the theoretical relationship for determining the plowing resistance, both of certain working bodies of a section, and of a whole plow. The method proposed for multistage plowing that implies loosening the subsoil provides a decrease in plowing resistance by 8.3-9.8\% compared to the existing double-depth plowing followed by loosening the subsoil.
\end{abstract}

\section{Introduction}

The most promising way of cultivating virgin soil and increasing soil fertility is multistage plowing. One of the performance indicators here is the quality loosening of each of the horizons [1, 2]. However, the existing methods of multistage plowing require high energy costs, which hinders their implementation into production [3-5].

A widely used method of double-depth plowing [6-8] includes a sequential removal of uppermost and lowermost soils from the soil monolith, turnover and stacking with a change in the relative position along the vertical. The method does not provide high quality soil cultivation due to a pressure pan ("plow sole") representing a layer of soil compacted when the soil layer is removed from the monolith with a plowshare.

The compacted soil layer prevents the penetration of air and moisture into the subsurface root layer, which reduces the yield of agricultural crops. In addition, when a plow sole is formed, the plow wastes energy, which reduces the performance of the unit and increases fuel consumption for soil cultivation.

There is also a method of multistage plowing [6-8] that includes a sequential removal of uppermost and middle soils from the monolith, turnover and stacking with a change in the relative position along the vertical, as well as loosening the bottom soil. Moreover, the uppermost soil rests on the bottom of the furrow on top of the loosened soil layer resulting from the previous subsoil slice to roll over, and the subsoil rests on top of the previous uppermost soil.

With this method of multistage plowing, a pressure pan ("plow sole"), representing a layer of soil compacted when the subsoil is separated from the monolith with a plowshare, is removed by subsequent loosening of the bottom soil.

Energy costs that are inefficiently consumed by the plow, first for the formation of the compacted soil layer, and then for its subsequent loosening, reduce the performance of the unit and increase fuel consumption, that is, worsen the economic performance of the plow.

A new method of multistage soil cultivation implies loosening the bottom soil and the subsoil horizon simultaneously, followed by overturning the bottom soil without cutting, which prevents the formation of a plow sole and reduces the plowing resistance and energy consumption of the plow.

The proposed method of multistage tillage involves the following steps in accordance with Figure 1:

- first (Fig. 1, a), the uppermost soil I is cut out, position 1, the layer crumbles (Fig. 1, b) and moves forward from position 1 to position 2 onto the untreated soil layer;

- the bottom soil II and the subsurface horizon III, position 3, are loosened (Fig. 1, b, c);

- the bottom soil II, position 4, is separated from the loosened soil, position 3, (Fig. 1, c), lifts and rolls over to the uppermost soil I and occupies position 6 , followed by an open furrow to be cut, position 7 (Fig. 1, d); c, d);

- the loosened subsurface horizon III stays up (Fig. 1,

- the top soil I, position 8, moves forward being overturned into an open furrow, position 7 , and takes position 9 (Fig. 1, d, e);

- the bottom soil II and the subsurface horizon III, position 10, are loosened (Fig. 1, e, f);

- the bottom soil II, position 11, is separated from the loosened soil, position 10, (Fig. 1, f), moves forward

*orresponding author: erzamaev_mp@mail.ru 
while overturned to the uppermost soil I, position 9, and occupies position 13, with an open furrow 14 to be simultaneously cut (Fig. 1, g);

- the loosened subsurface horizon III stays up (Fig. 1, $\mathrm{f}, \mathrm{g})$.

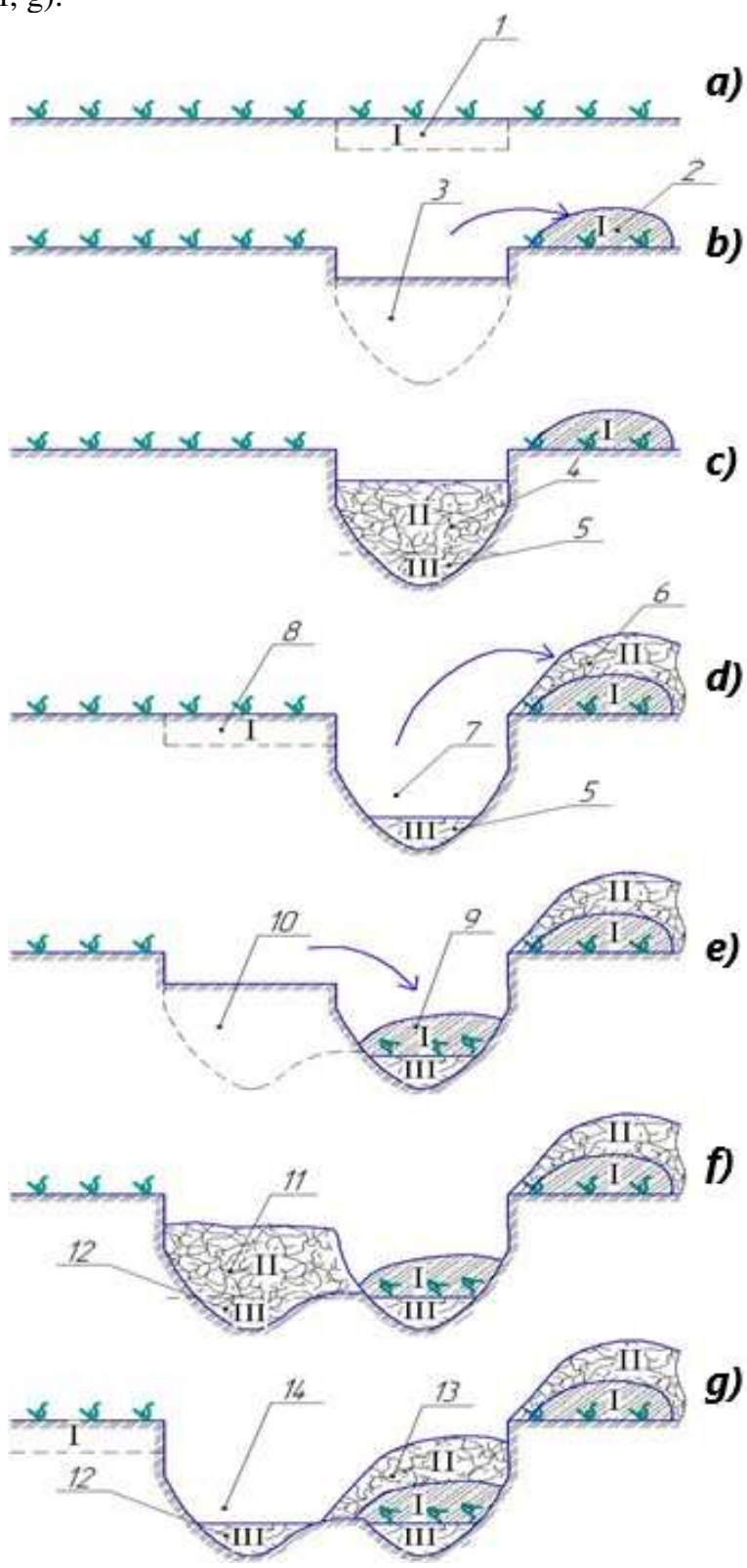

Fig. 1. Schematic for multistage soil cultivation with loosening of the subsoil horizon: I - topsoil; II - bottom soil; III - subsurface horizon
Further, the technological process of soil cultivation is repeated following the previous operations of positions 8-14 (Fig. 1, d, e, f, g).

\section{Materials and methods}

Based on the energy evaluation of the options for the arrangement of the working bodies and in order to conduct laboratory-field and field studies aimed at the method of multistage cultivation by a PRUN-5-45 plow, a combined plow was designed and manufactured (Fig. 2) for multistage plowing with loosening of the subsoil horizon.

The main technical characteristics of the combined plow for multistage soil cultivation are shown in Table 1.

The combined plow consists of a frame 1 (Fig. 2), a hitch 2, a vertical regulator 3 with a support wheel 4 , working bodies: bladeless loosening bodies of a lower tier 5 and ploughshare-moldboard bodies of an upper tier 6 with mounting brackets 7 on the frame 1 .

On the plow frame, the last is the body of the upper tier, which forms a semi-furrow. The unit is driven by the tractor's right-hand propellers along this semifurrow. During the subsequent run down the field, the semi-furrow is processed by the body of the lower tier.

The upper tier body is designed for moldboard processing of the uppermost soil and is installed in the bracket.

Table 1. Technical characteristics of the experimental combined plow

\begin{tabular}{|l|c|}
\hline \multicolumn{1}{|c|}{ Index } & Index value \\
\hline Aggregated with tractors of class & 3 and 4 \\
\hline Working speed, m/s & $1.5-3.0$ \\
\hline Furrow width, $\mathrm{m}$ & 1.8 \\
\hline Tillage depth, $\mathrm{m}$ & \\
\hline $\begin{array}{l}\text { Overall dimensions of the } \\
\text { machine, m, no more: }\end{array}$ & 5.45 \\
\hline - length & 3.0 \\
\hline - width & 1.81 \\
\hline - height & 1,410 \\
\hline Machine weight, kg & 0.84 \\
\hline $\begin{array}{l}\text { Distance from the support plane of } \\
\text { the chisels to the lower plane of } \\
\text { the frame, } \mathrm{m}\end{array}$ & 1.07 \\
\hline $\begin{array}{l}\text { Distance between homogeneous } \\
\text { adjacent working bodies along the } \\
\text { main beam, } \mathrm{m}\end{array}$ & \\
\hline
\end{tabular}




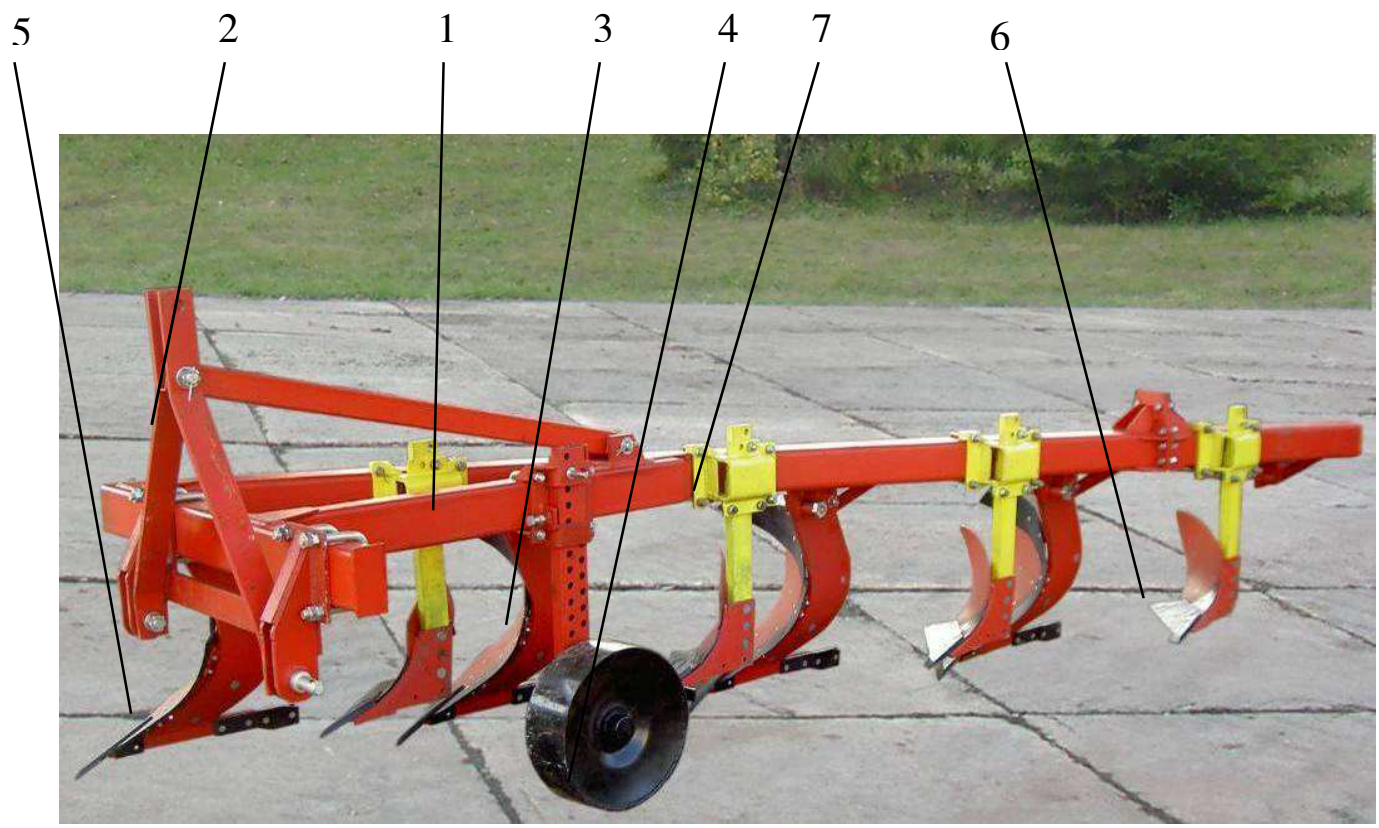

Fig. 2. Combined plow: 1 - frame; 2 - hitch; 3 - vertical regulator; 4 - support wheel; 5 - bladeless loosening body of a lower tier; 6 - body of the upper tier; 8 - mounting bracket of the upper tier

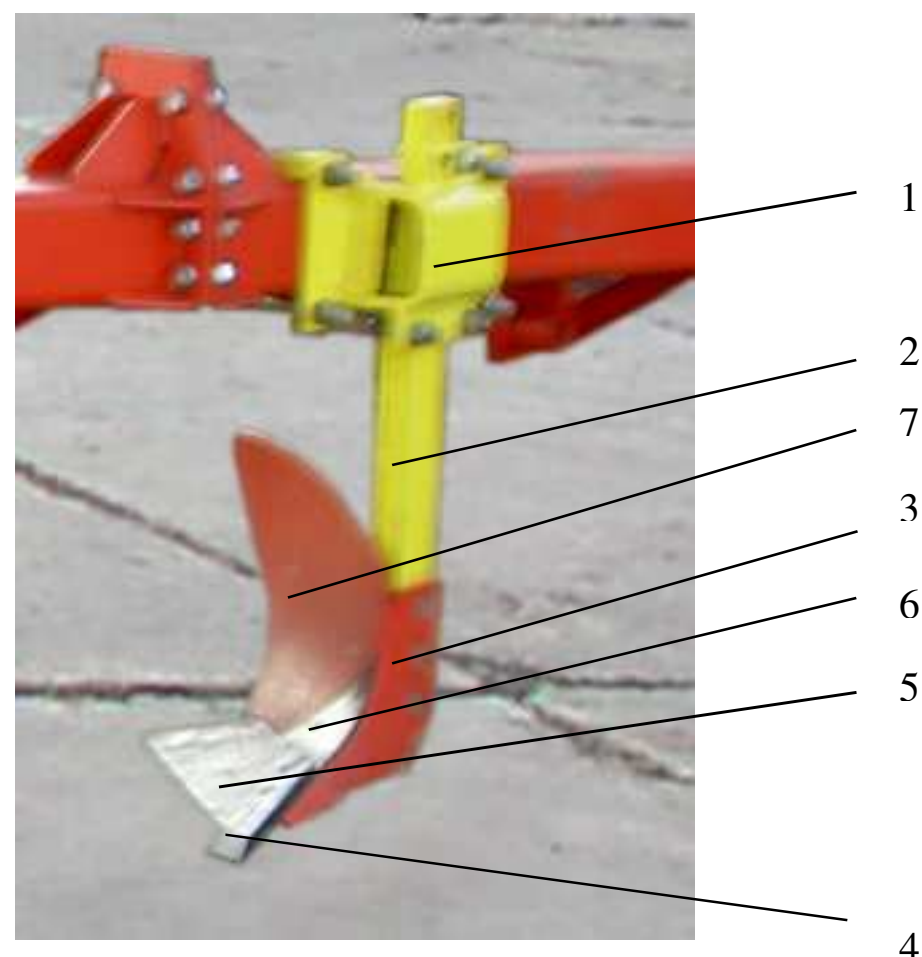

Fig. 3. Upper tier body: 1 - bracket; 2 - rack; 3 - shoe; 4 - share chisel; 5 - share; 6 - moldboard breast; 7 - moldboard wing 


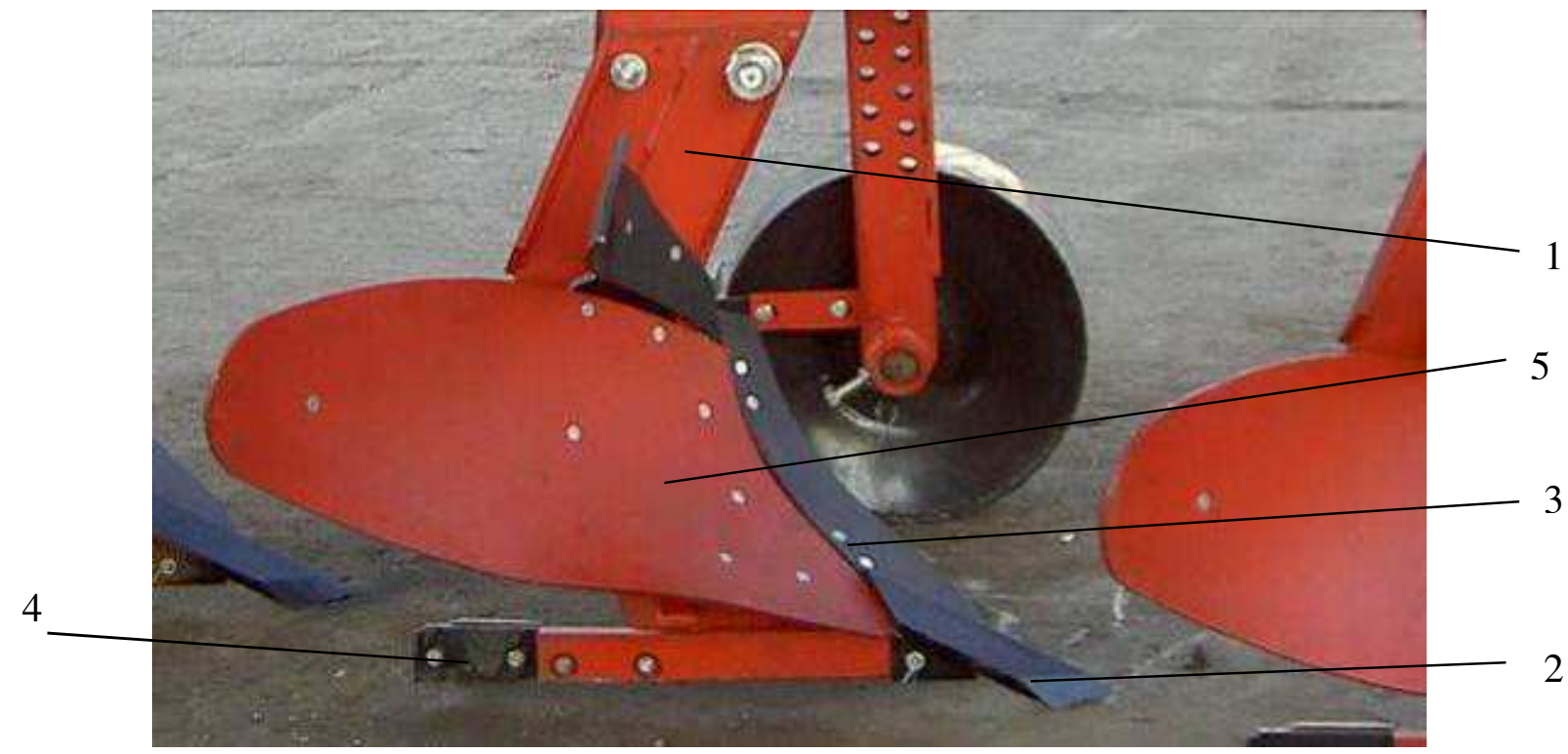

Fig. 4. Lower tier body: 1 - stilt; 2 - chisel; 3 - ripper breast; 4 - field board; 5 - moldboard wing

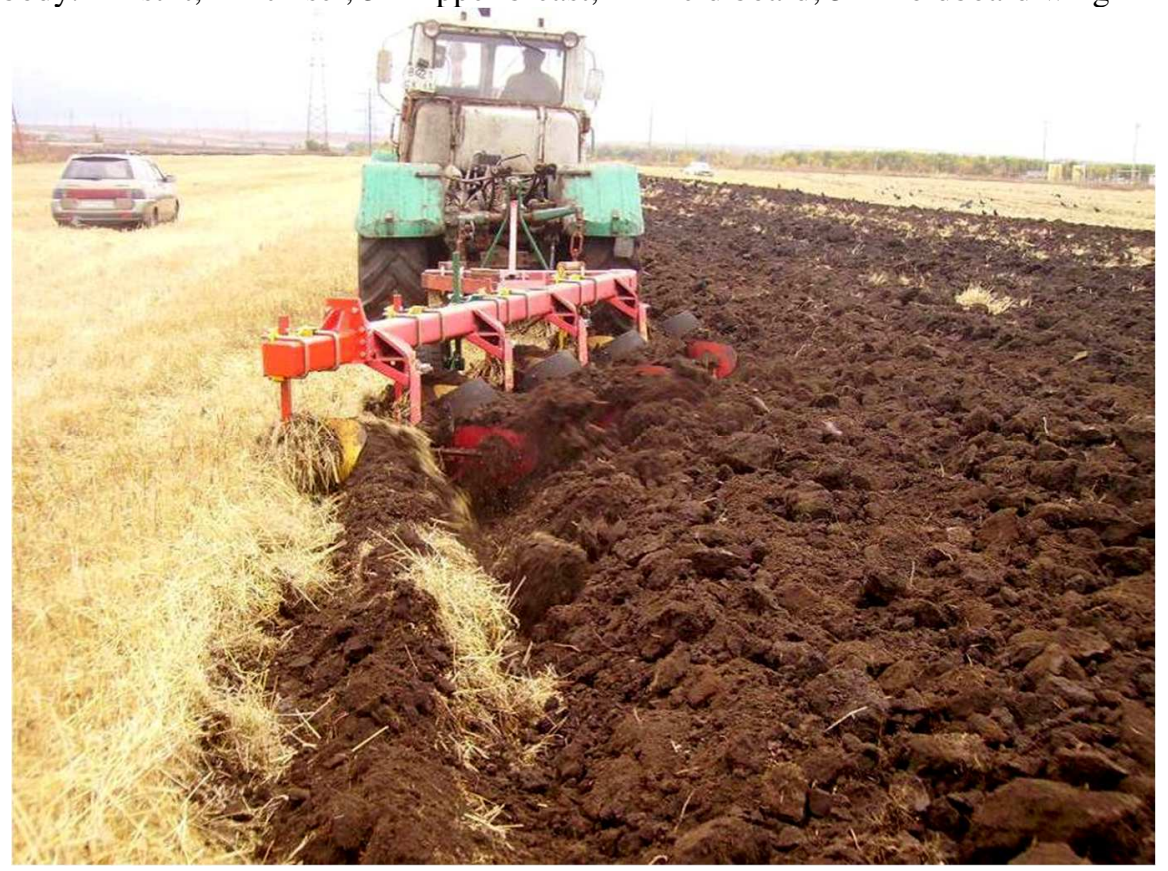

Fig. 5. Combined plow drawn by the T-150K tractor

Technological tillage processes with a multistage plow are carried out as follows. When the plow moves forward, the upper tier body separates the uppermost soil with a ploughshare and crumbles it with a shin of the moldboard, turns it over and leaves it in the bottom of the furrow opened by the previous body of the lower tier. The subsequent plow body of the lower tier separates the bottom layer of soil, crumbles, rolls over and leaves it on top of the soil layer in the furrow. The soil layer from below is separated along natural cracks in the soil, formed by the deforming effect of the chisel, loosening the subsoil horizon.

In mass production, there are no plows designed for a similar multistage plowing with loosening of the subsoil, therefore, to compare efficiency, it is necessary to use a multistage plow and a ripper.

\section{Findings}

The energy consumed for the proposed method of multistage tillage was determined by comparing the plowing resistance of the sections of the working bodies according to the existing and proposed methods of multistage plowing with loosening of the subsoil on a strain transducer.

The plowing resistance of one section of the working bodies according to the existing method of multistage plowing with loosening of the subsurface horizon involved the plowing resistances of the ploughsharemoldboard body of the upper tier when cultivating the soil to a depth of $0.12 \mathrm{~m}$, in the ploughshare-moldboard 
body of the lower tier when cultivating the soil to a depth of $0.30 \mathrm{~m}$ and a ripper to a depth of $0.45 \mathrm{~m}$. The plowing resistance of one section of the working bodies according to the proposed method of multistage soil cultivation involved the plowing resistances of the ploughshare-moldboard body of the upper tier when cultivating the soil to a depth of $0.12 \mathrm{~m}$ and of a bladeless body of the lower tier when cultivating the soil to a depth $0.45 \mathrm{~m}$.

Figure 6 shows the relationship between a change in the plowing resistance of the sections of the working bodies according to the existing and proposed methods of multistage plowing with loosening of the subsurface horizon and the speed of the plowing unit.

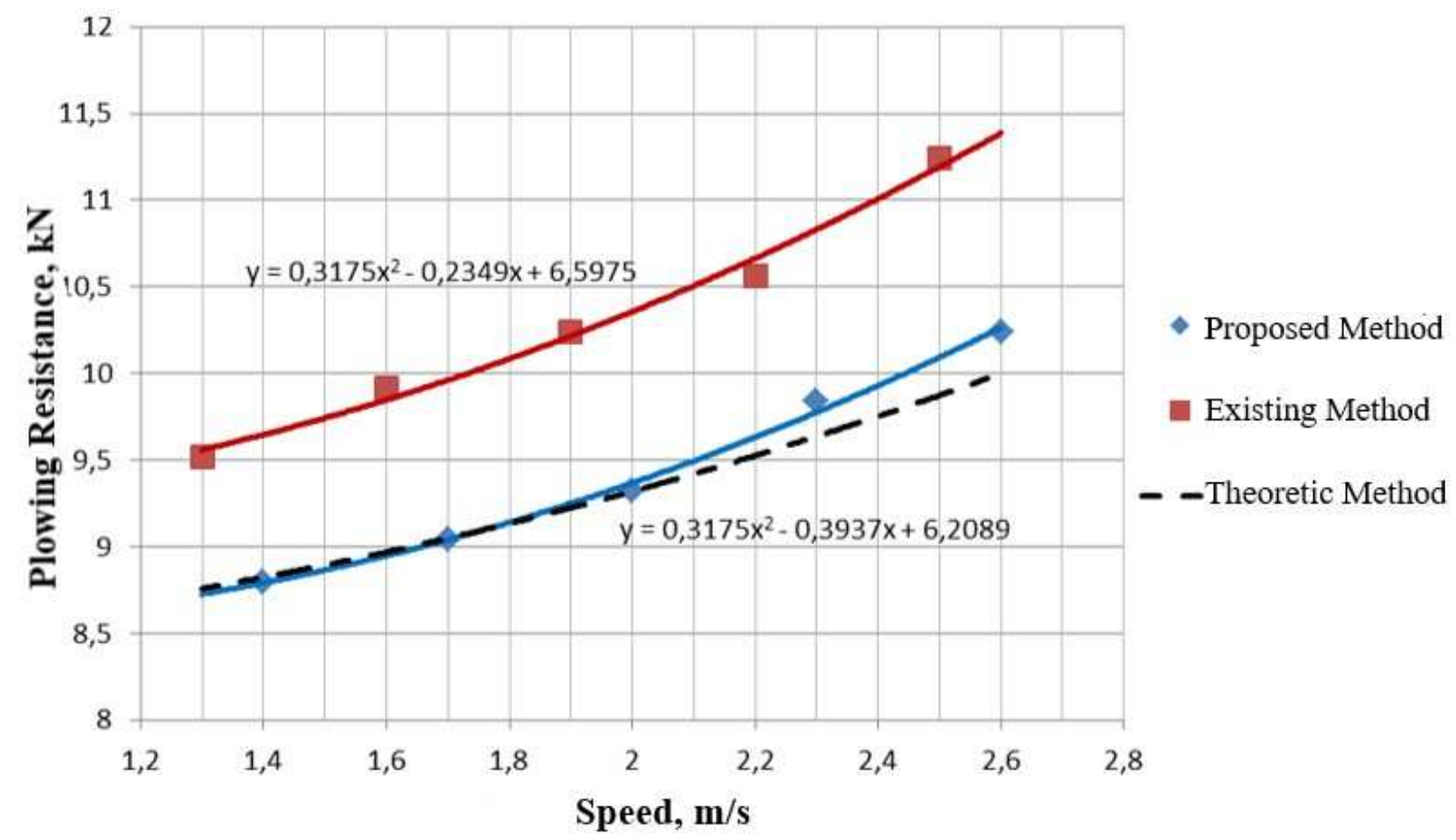

Fig. 6. Plowing resistance of the sections of the working bodies according to the existing and proposed methods of multistage tillage vs speed

The data show that the proposed method of multistage soil cultivation in comparison with the existing method of multistage soil cultivation provides a decrease in plowing resistance by $8.3-9.8 \%$.

The effectiveness of multistage tillage with a combined plow was evaluated by comparing the performance of plowing units made up of compared plows, alternately aggregated with the same tractor in areas located on the same field. Based on the results of a comparative energy assessment of PNYa-4-42 mounted plows and the combined plow at various speeds in the range of $1.3-2.7 \mathrm{~m} / \mathrm{s}$, the combined plow gave lower specific energy costs for cultivating a unit of soil volume by an average of $10.6-17.9 \%$ (Fig. 7).

Prior theoretical aspects $[4,7,9,10]$ are in good agreement with the experimental values of the plowing resistance of the section of working bodies, which fully confirms the validity of theoretical assumptions.

Thus, the energy efficiency of multistage soil cultivation by the proposed combined plow with optimal technological parameters is confirmed. 


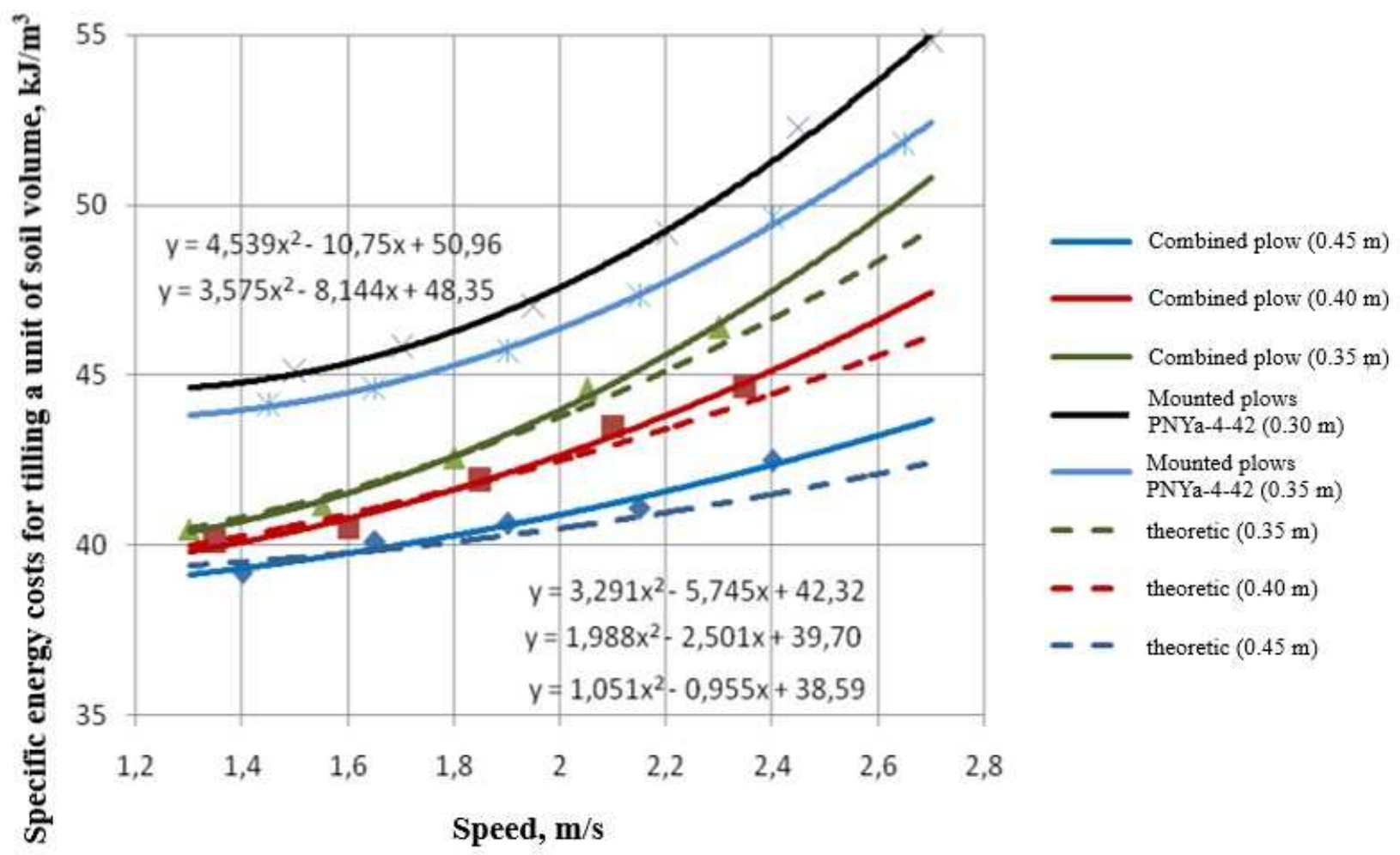

Fig. 7. Specific energy costs vs speed and depth of soil cultivation

\section{Conclusion}

The developed technological process of multistage soil cultivation will provide a decrease in plowing resistance and better quality indicators of soil cultivation, increase the productivity of the plowing unit and reduce fuel consumption for soil cultivation.

Field studies have established that multistage soil cultivation with a combined plow requires lower specific energy costs by an average of 10.6-17.9\% at speeds of $1.5-2.5 \mathrm{~m} / \mathrm{s}$. In this case, the soil moisture reserve increases to $20 \%$.

\section{References}

1. S.I. Korzhov, Influence of soil cultivation on biological processes, Bulletin of the Voronezh State Agrarian University, 3, 14-17 (2010)

2. V. Bulgakov et al., Experimental Investigation of Plow-Chopping Unit, Agriculture, 11(1), 30 (2021)

3. N.I. Dzhabborov, A.V. Dobrinov, P.N. Jabborov, Research and modeling of the wear process of parts of the soil tillage working implements, IOP Conference Series: Earth and Environmental Science, 699(1), 012038 (2021)
4. Y.P. Lobachevsky et al., Ploughing quality and energy consumption depending on plough bodies type, IOP Conference Series: Materials Science and Engineering, 1030(1), 012154 (1030)

5. M.M. Ilyasov, A.Kh. Yapparov, Resource-saving basic tillage on chernozems of the Republic of Tatarstan, Fertility, 3 (2010)

6. B. Mirzaev et al., Technologies and technical means for anti-erosion differentiated soil treatment system, E3S Web of Conferences, 97, 05036 (2019)

7. M.P. Erzamaev et al., Influence of technological parameters of multistage tillage on energy costs, Bulletin Samara State Agricultural Academy, 2, 312 (2018)

8. P. Bucki et al., Impact of soil management practices on yield quality, weed infestation and soil microbiota abundance in organic zucchini production, Scientia Horticulturae, 281, 109989 (2021)

9. M.P. Erzamaev et al., Universal equipment for determining traction resistance of working bodies and their combinations designed for soil treatment, BIO Web of Conferences, 17, 00010 (2020)

10. W.S. Kim et al., Influence of soil moisture content on the traction performance of a $78-\mathrm{kW}$ agricultural tractor during plow tillage, Soil and Tillage Research, 207, 104851 (2021) 